\title{
PERANCANGAN JARINGAN SENSOR NIRKABEL (JSN) UNTUK MEMANTAU SUHU DAN KELEMBABAN MENGGUNAKAN nRF24LO1+
}

\author{
Dwi Intan Af'idah" ${ }^{1)}$, Adian Fatchur Rochim ${ }^{2)}$, Eko Didik Widianto ${ }^{2)}$ \\ Program Studi Sistem Komputer, Fakultas Teknik, Universitas Diponegoro \\ Jalan Prof. Sudharto, Tembalang, Semarang, Indonesia
}

\begin{abstract}
The environmental condition in a large areas often requires the monitoring. For example, in the case of greenhouse were used to cultivation experiments, fertilization experiments, plant resistance experiments, tissue culture experiments, experimental planting of crops in the off-season, and it needs equipment to monitor and control the environmental conditions to suit the characteristics required environment. The extent of land that is must be monitored, making it needs distribute the monitor at some point so that monitoring of environmental conditions can cover the entire desired area. This is the basis for the design of wireless sensor network for monitoring temperature and humidity using the communication module nRF24L01 +.

The system consists of hardware for measuring the temperature and humidity at some point in a certain area. The system is divided into several sections that is referred to as nodes. Node in the system is divided into two functions, namely the sensor node and the concentrator node.. There are two the sensor nodes which will serve to data of temperature and humidity in separate areas and transmit data to the concentrator node. The communication between nodes is done using a module nRF24L01+.

The design of communication protocol designed to connect between nodes concentrator with a sensor node capable of running properly. This makes the system capable of monitoring temperature and humidity through a web page, so it can be known conditions of temperature and humidity at some point at the maximum range of 93 meters.
\end{abstract}

Keywords: Wireless Sensor Networks, Temperature and Humidity Monitor, nRF14L01+.

\section{PENDAHULUAN}

Pemantauan kondisi lingkungan pada suatu area tertentu sering kali diperlukan. Misalnya, area pertanian yang memerlukan suhu dan kelembaban tertentu agar tanaman di area tersebut dapat tumbuh subur. Salah satu area pertanian yang sangat memerlukan adanya pemantauan kondisi lingkungan adalah greenhouse. Greenhouse yang digunakan di Indonesia sebagian besar digunakan untuk penelitian percobaan budidaya, percobaan pemupukan, percobaan ketahanan tanaman terhadap hama maupun penyakit, percobaan kultur jaringan, percobaan persilangan atau pemuliaan, percobaan hidroponik dan percobaan penanaman tanaman di luar musim oleh para mahasiswa, para peneliti, para pengusaha dan praktisi di semua bidang pertanian.

Pada kasus Greenhouse, diperlukan peralatan untuk memantau dan mengontrol kondisi lingkungan agar sesuai dengan karekateristik lingkungan yang dibutuhkan tanaman. Kondisi lingkungan yang perlu dikontrol diantaranya adalah suhu dan kelembaban udara. Luasnya lahan yang akan dipantau, membuat kondisi lingkungan pada beberapa titik tidak selalu sama. Hal ini menjadikan perlu adanya pemantauan pada beberapa titik sehingga pemantauan kondisi lingkungan bisa mencakup seluruh area yang dinginkan. Hal ini yang menjadikan dasar untuk melakukan pengembangan teknologi dalam hal pemantauan kondisi lingkungan di suatu area. ${ }^{[4]}$

Penggunaan sistem komunikasi nirkabel (wireless) sebagai media komunikasi pada sistem jaringan komputer semakin populer sekarang ini. Aplikasi teknologi nirkabel membuat informasi dan komunikasi menjadi cepat dan mudah. Teknologi yang akan dirancang adalah sebuah sistem pemantauan suhu dan kelembaban di beberapa titik area yang berbeda. Sistem ini mendukung sensor di beberapa titik, yang hasil akuisinya akan dikirimkan ke komputer secara nirkabel. Sedangkan sistem monitoring alat ini ditampilkan pada halaman web menggunakan bahasa HTML (Hypertext Markup Language). Komunikasi yang digunakan dalam sistem ini adalah jaringan sensor nirkabel menggunakan nRF24L01+.

Perbandingan nRF24L01+ dengan modul komunikasi nirkabel lainnya, misalnya XBee adalah harga dari nRF24L01 lebih murah, tapi pemrograman yang lebih rumit serta jangkauannya lebih pendek yaitu 100 meter untuk nRF24L01+ dan 200 meter untuk XBee. Namun, kebutuhan jangkauan komunikasi yang akan diterapkan pada area yang tidak terlalu luas, misalnya pada lahan pertanian, menjadi alasan pemilihan modul nRF24L01+ sebagai pengoptimalan fungsional dan biaya yang diperlukan.

Adapun tujuan penelitian yang akan dicapai adalah sebagai berikut, mempelajari dan menerapkan jaringan sensor nirkabel menggunakan modul nRF24L01+, merancang protokol untuk komunikasi menggunakan jaringan sensor nirkabel, dan merancang alat untuk memantau suhu dan kelembaban di beberapa titik area menggunakan jaringan sensor nirkabel dimana pemantauan dapat dilakukan dengan menampilkan data pada halaman web.

\section{DASAR TEORI}

\subsection{Jaringan Sensor Nirkabel}

Jaringan sensor nirkabel merupakan suatu jejaring nirkabel menggunakan alat berupa sensor yang bekerjasama untuk memantau kondisi tertentu seperti temperatur, suara, cahaya, tekanan dan lain-lain. ${ }^{[3]}$ Jaringan sensor nirkabel merupakan suatu jaringan sensor 
yang terdiri dari node sensor yang disebar pada beberapa titik, dan dapat melakukan komunikasi tanpa kabel. Jadi konsep sederhana dari suatu jaringan sensor nirkabel adalah berdasarkan fungsi pengindraan, CPU dan Radio.

Secara umum jaringan sensor nirkabel terdiri dari sejumlah node sensor dan sebuah node koordinator. Seluruh informasi dikirimkan ke node koordinator dari satu node sensor secara langsung melalui node-node lain sebagai pengulangan di dalam satu jaringan. Node sensor merupakan bagian terpenting salam suatu jaringan sensor nirkabel, karena dari node sensor inilah informasi data sensor akan dikumpulkan, dikonversi ke dalam informasi digital, kemudian diolah dan dikirimkan sebagai data yang telah diproses. ${ }^{[6]}$

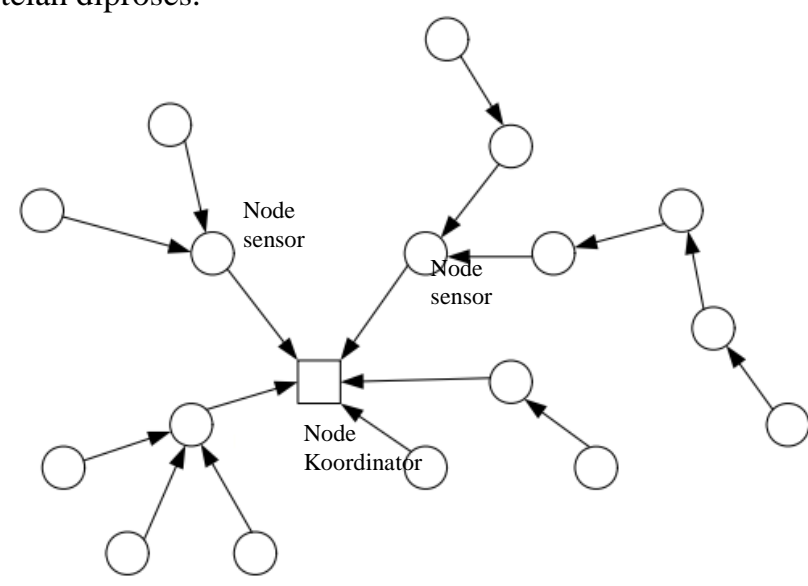

Gambar 1 Struktur jaringan sensor nirkabel ${ }^{[6]}$

\subsection{Modul NRF24L01+}

Modul nirkabel NRF24L01+ adalah sebuah modul komunikasi yang memanfaatkan gelombang RF $2,4 \mathrm{GHz}$ ISM (Industrial, Scientific and Medical). Modul ini menggunakan antarmuka SPI (Serial Peripheral Interface) untuk berkomunikasi. NRF24L01+ mengintegrasikan pengirim lengkap $2.4 \mathrm{GHz} \mathrm{RF}$, RF pengumpul, dan akselerator protokol berupa Enhanced Shockburst yang mendukung antarmuka SPI kecepatan tinggi untuk kontroler aplikasi. NRF24L01+ memiliki solusi terkait daya berupa daya ultra rendah yang memungkinkan daya tahan baterai berbulan-bulan. Modul ini dapat digunakan untuk pembuatan perangkat tambahan komputer, piranti permainan, piranti fitnes dan olahraga, mainan anak-anak dan alat lainnya.

Modul nirkabel NRF24L01+ memiliki 8 buah pin, diantaranya: VCC (3,3V DC), GND, CE, CSN, MOSI, MISO, SCK, dan IRQ. Modul ini memiliki beberapa fitur antara lain;

- Beroperasi pada pada ISM 2.4 GHZ

- Kecepatan pengiriman data 250kbps hingga 2 Mbps

- Operasi daya ultra rendah

- Penanganan paket data otomatis

- Penanganan transaksi paket otomatis

- Sumber daya hanya $1,9 \mathrm{~V}$ to $3,6 \mathrm{~V}$

- Jangakauan pengiriman: $100 \mathrm{~m}$ di tempat terbuka. ${ }^{[12]}$

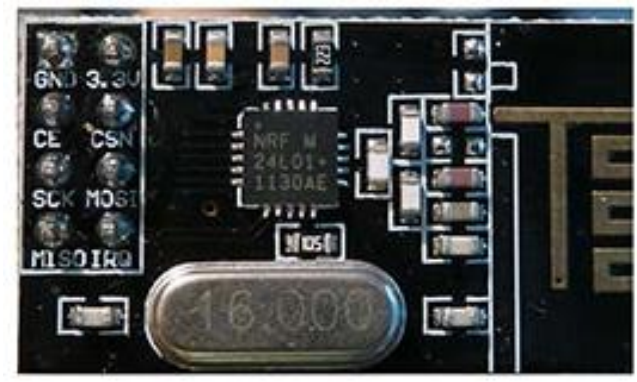

Gambar 2 Modul NRF24L01+ ${ }^{[12]}$

\subsection{Arduino Uno}

Arduino Uno menggunakan ATmega16U2 yang diprogram sebagai pengubah USB-to-serial untuk komunikasi serial ke komputer melalui port USB.

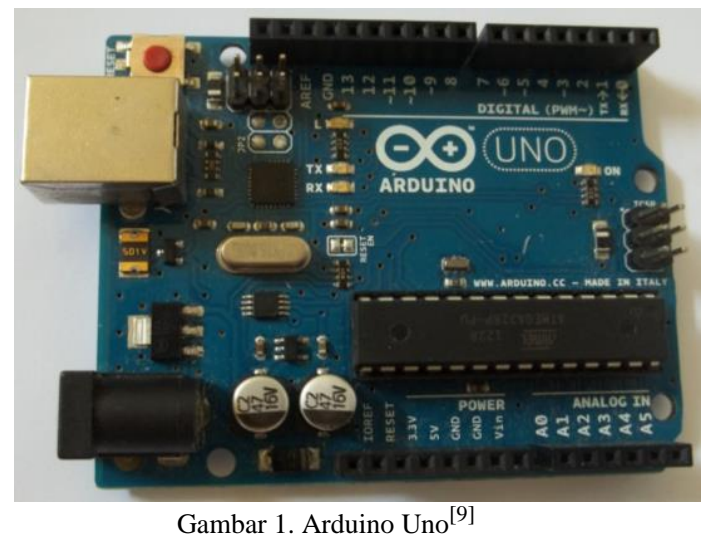

Data teknis board Arduino UNO R3 berdasarkan adalah sebagai berikut :

1. Mikrokontroler

: ATMEGA328.

2. Tegangan Operasi

: $5 \mathrm{~V}$.

3. Tegangan Masukan (rekomendasi) : $7-12 \mathrm{~V}$.

4. Tegangan Masukan (limit)

5. Pin digital $\mathrm{I} / \mathrm{O}$

: $6-20 \mathrm{~V}$. (6 diantaranya pin PWM)

6. Pin Masukan Analog

7. Arus DC per pin $\mathrm{I} / \mathrm{O}$

8. Arus DC untuk pin $3.3 \mathrm{~V}$

9. Memory Kilat $: 14$

10. SRAM

11. EEPROM

12. Kecepatan Clock

: $40 \mathrm{~mA}$.

: $150 \mathrm{~mA}$

: $32 \mathrm{~KB}$.

: $2 \mathrm{~KB}$.

: $1 \mathrm{~KB}$.

: $16 \mathrm{MHz}{ }^{[9]}$

\subsection{Sensor Suhu dan Kelembaban DHT 11}

DHT11 Sensor ini merupakan sensor dengan kalibrasi sinyal digital yang mampu memberikan informasi suhu dan kelembaban. Sensor ini tergolong komponen yang memiliki tingkat stabilitas yang sangat baik, apalagi digandeng dengan kemampuan mikrokontroler 8 bit seperti Arduino. DHT 11 adalah sensor dengan kualitas terbaik, respon pembacaan yang cepat, dan kemampuan anti interferensi, dengan harga yang sangat terjangkau. 


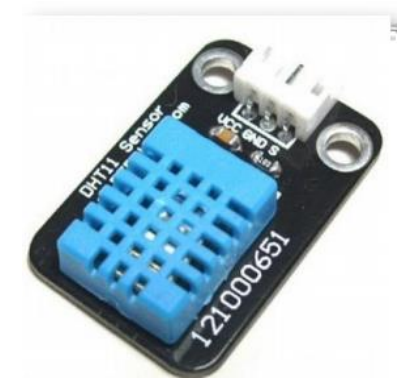

Gambar 4. Sensor suhu dan kelembaban DHT $11^{[13]}$

Spesifikasi DHT11 adalah sebagai berikut:

1. Sumber Tegangan : $+5 \mathrm{~V}$

2. Kisaran Suhu :0 $-50{ }^{\circ} \mathrm{C}$ kesalahan sekitar $\pm 2{ }^{\circ} \mathrm{C}$

3. Kisaran Kelembaban :20-90\% RH kesalahan sekitar $\pm 5 \% \mathrm{RH}$

4. Interface : Digital ${ }^{[11]}$

\subsection{DFRduino Ethernet Shield}

Arduino Ethernet Shield memungkinkan sebuah board Arduino untuk terhubung dengan internet. Modul ini dibuat berdasarkan ethernet Wiznet W5100. Wiznet W5100 menyediakan sebuah jaringan dengan kemampuan TCP (Transmission Control Protocol) dan UDP (User Datagram Protocol) yang mendukung sampai dengan 4 koneksi soket secara bersamaan.

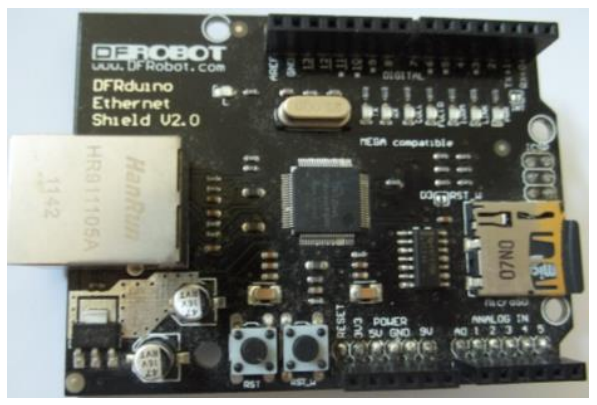

Gambar 5. Ethernet Shield DFRduin ${ }^{[8]}$

Ethernet Shield ini terhubung dengan papan Arduino menggunakan header dengan kaki yang panjang yang menembus papan Arduino. Hal Ini untuk menjaga sususan pin dan memungkinkan papan lain untuk ditumpukkan di atasnya. Arduino menggunakan pin digital 10, 11, 12 dan 13 (SPI) untuk berkomunikasi dengan keping W5100 pada Ethernet Shield. Pin-pin tersebut tidak bisa digunakan untuk keperluan yang lain. Modul ini menyediakan port standar RJ45. Tombol reset di modul ini akan membuat diulangnya program W5100 dan papan Arduino. ${ }^{[8]}$

\section{PERANCANGAN SISTEM}

\subsection{Perancangan Perangkat Keras}

Perancangan perangkat keras merupakan perancangan jaringan sensor nirkabel untuk memantau suhu dan kelembaban. Perancangan perangkat lunak merupakan perancangan program yang dibutuhkan oleh mikrokontroller ATMega328 serta aplikasi Personal Computer sebagai antarmuka.
Diagram blok perancangan sistem pengukur suhu dan kelembaban dapat dilihat pada Gambar 6.

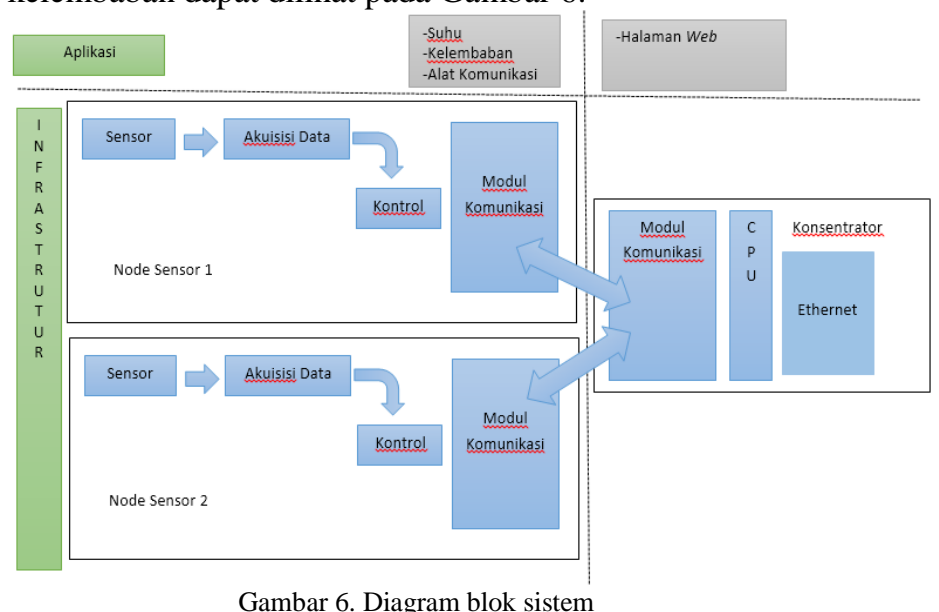

3.1.1 Arduino Uno

Tabel 1. Arduino Uno sebagai node sensor 1 dan node sensor 2

\begin{tabular}{|l|l|}
\hline \multicolumn{1}{|c|}{ Pin Arduino } & \multicolumn{1}{|c|}{ Peripheral } \\
\hline Pin digital $6,7,11,12,13$ & nRF24L01+ \\
\hline Pin digital 2 & DHT11 \\
\hline Pin A0 & LED \\
\hline
\end{tabular}

Tabel 2. Arduino Uno sebagai koordinator

Tabel 2. Arduino Uno sebagai koordinator
\begin{tabular}{|l|l|}
\hline \multicolumn{1}{|c|}{ Pin Arduino } & \multicolumn{1}{c|}{ Peripheral } \\
\hline Pin digital $6,7,11,12,13$ & nRF24L01+ \\
\hline Pin digital $10-13$ & Ethernet \\
\hline
\end{tabular}

3.1.2 nRF24L01+ pada Node Sensor

Tabel 3. Pin NRF24L01+ pada node sensor

\begin{tabular}{|l|l|}
\hline \multicolumn{1}{|c|}{ Pin Arduino } & \multicolumn{1}{c|}{ Pin nRF24L01+ } \\
\hline Pin digital 6 & CSN \\
\hline Pin digital 7 & CE \\
\hline Pin digital 11 & MOSI \\
\hline Pin digital 12 & MISO \\
\hline Pin digital 13 & SCK \\
\hline
\end{tabular}

3.1.3 Sensor Suhu dan Kelembaban DHT 11 dan LED Tabel 4. Sensor DHT 11

\begin{tabular}{|l|l|}
\hline \multicolumn{1}{|c|}{ Pin Arduino } & \multicolumn{1}{c|}{ Pin DHT11 } \\
\hline Pin digital 2 & DATA \\
\hline Pin A0 & LED \\
\hline
\end{tabular}

3.1.4 nRF24L01+ dan Ethernet pada Node Koordinator Tabel 5. NRF24101+ dan Shield Ethernet

\begin{tabular}{|l|l|l|}
\hline \multicolumn{1}{|c|}{ Pin Arduino } & Pin Ethernet & \multicolumn{1}{c|}{ Pin nRF24L01+ } \\
\hline Pin digital 6 & & CSN \\
\hline Pin digital 7 & & CE \\
\hline Pin digital 10 & Pin digital 1 & \\
\hline Pin digital 11 & Pin digital 2 & MOSI \\
\hline Pin digital 12 & Pin digital 3 & MISO \\
\hline Pin digital 13 & Pin digital 4 & SCK \\
\hline
\end{tabular}

\subsection{Perancangan Protokol Komunikasi}

Proses perancangan protokol komunikasi akan menjabarkan rancangan protokol komunikasi yang akan digunakan untuk melakukan komunikasi antar node koordinator dengan node sensor. Pada Gambar 5 ditunjukkan diagram blok protokol komunikasi. 


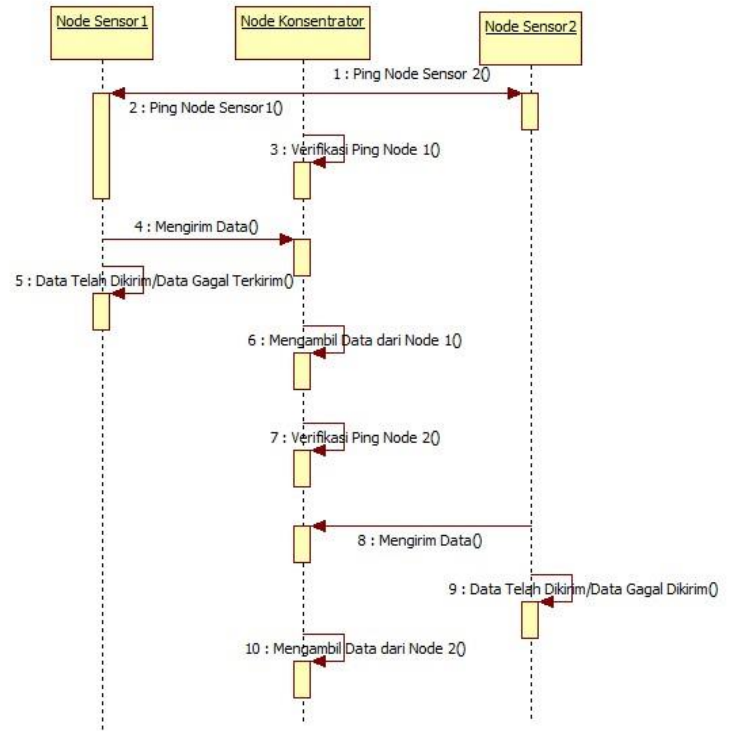

Gambar 5. Diagram protokol komunikasi

\subsection{Perancangan Perangkat Lunak}

Perancangan perangkat lunak merupakan perancangan program yang dibutuhkan oleh mikrokontroller ATMega328 pada sisi node sensor 1 dan node sensor 2 adalah untuk dapat membaca nilai suhu dan kelembaban dari sensor DHT11, nilai tersebut kemudian mampu dikirimkan melalui modul nRF24L01+ yang berfungsi sebagai transmitter ke koordinator. Sedangkan perancangan program yang dibutuhkan oleh mikrokontroller ATMega328 pada sisi koordinator adalah untuk menerima informasi nilai suhu dan kelembaban melalui modul nRF24L01+ yang berfungsi sebagai receiver, nilai tersebut kemudian diproses oleh ethernet untuk dapat ditampilkan di halaman website.

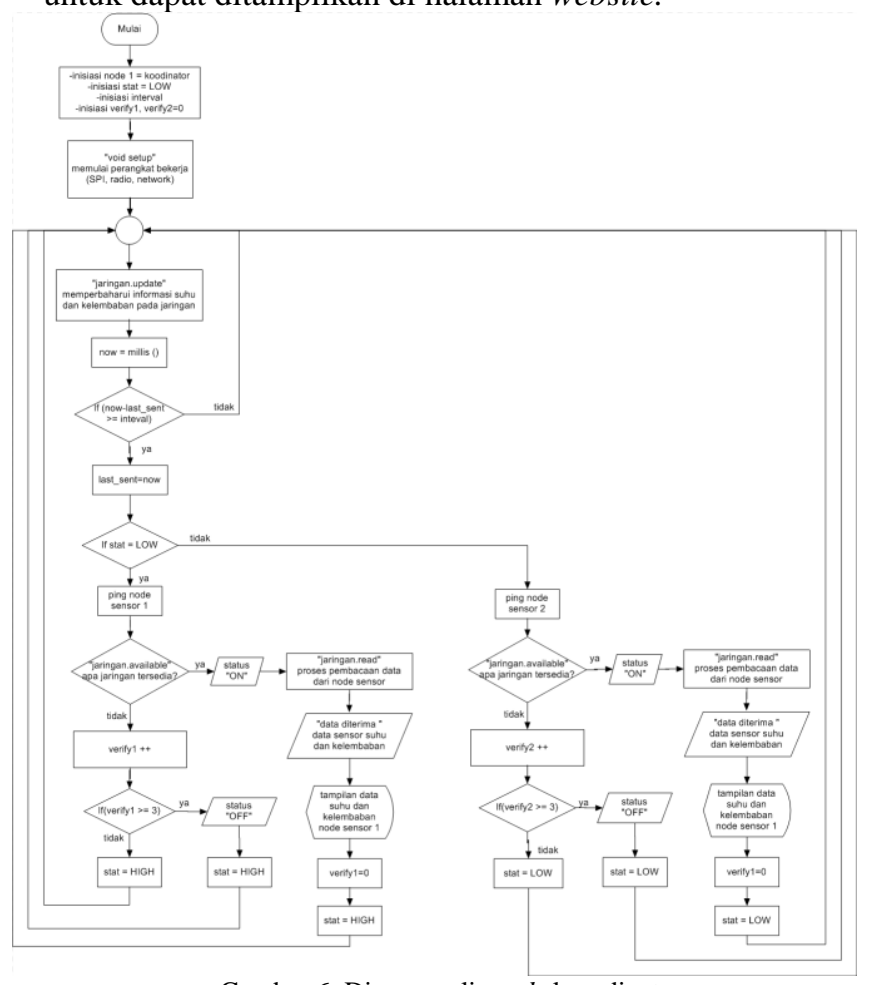

Gambar 6. Diagram alir node koordinator

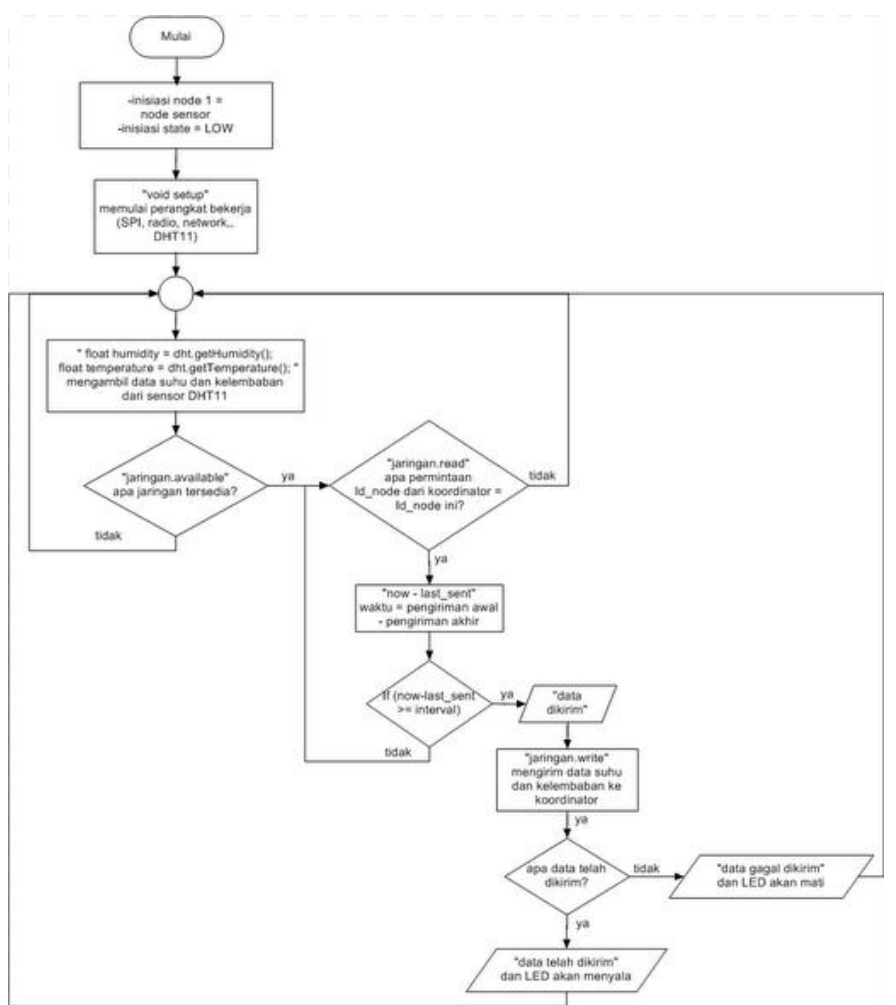

Gambar 7. Diagram alir node sensor

\section{IMPLEMENTASI DAN PENGUJIAN}

Implementasi sistem adalah hasil dari bagian perancangan, tahap yang membuat hasil dari perancangan sebelumnya. Pengujian dilakukan untuk menguji sistem apakah mampu bekerja sesuai dengan hasil perancangan yang telah dibuat dan mampu memberikan hasil pengolahan masukan dengan benar serta memberikan perilaku-perilaku serta keluaran sesuai kebutuhan.

\subsection{Implementasi Perangkat Keras dan Perangkat Lunak}

Implementasi sistem terdiri dari keseluruhan perangkat keras yang dirangkai untuk proses pengukur suhu dan kelembaban pada beberapa titik di area tertentu. Sistem ini terdiri dari 3 bagian, bagian ini selanjutnya disebut dengan node. Node pada sistem ini dibedakan menjadi 2 yaitu node sensor dan node koordinator. Dalam sistem ini, ada 2 node sensor yang akan berfungsi untuk melakukan pengambilan data suhu dan kelembaban pada area terpisah yang telah ditentukan.

Node koordinator terdiri dari arduino uno beserta Ethernet Shield dan NRF24L01+ sebagai modul komunikasi dan kabel USB beserta kabel UTP. Sedangkan node sensor terdiri arduino uno beserta Ethernet Shield dan NRF24L01+ sebagai modul komunikasi dan kabel USB beserta kabel UTP serta tambahan berupa DHT11 untuk mengambil data suhu dan kelembaban dan LED untuk menjadi penanda apakah sistem berjalan atau tidak.

Perangkat keras pertama yang diimplementasikan adalah papan sirkuit elektronik tempat komponenkomponen saling terhubung untuk menjadi sebuah sistem perangkat keras yang dibutuhkan, sesuai dengan port-port yang digunakan seperti yang dijelaskan dalam perancangan sistem pada Bab Perancangan Sistem. 

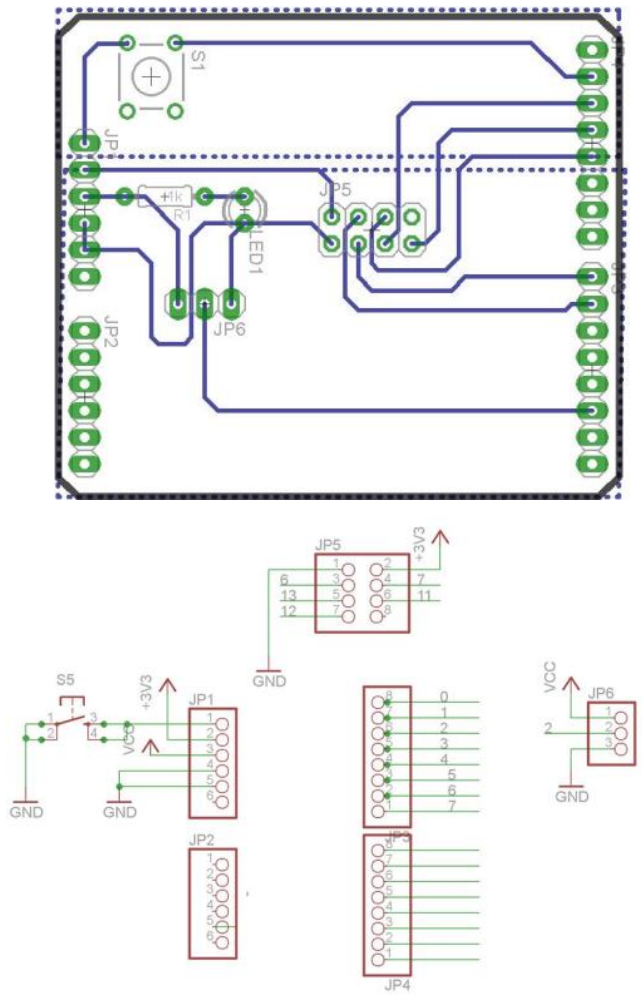

Gambar 8. Desain papan sirkuit elekronik

Setelah papan sirkuit elektronik selesai dibuat, kemudian komponen-komponen yang dibutuhkan dikumpulkan dan dipasang pada papan sirkuit elektronik dengan benar sesuai dengan perancangan sebelumnya. Pada Gambar 4.2 dan Gambar 4.3 ditunjukkan perbandingan gambar rancangan papan sirkuit elektronik dengan gambar setelah seluruh komponen dipasang pada papan sirkuit elektronik.

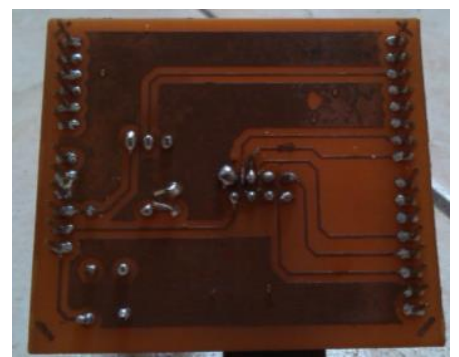

Gambar 9. Papan sirkuit elektronik yang sudah bisa digunakan

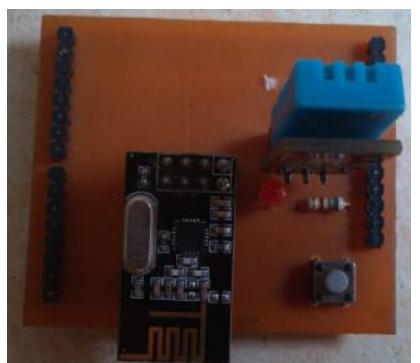

Gambar 10. Pemasangan komponen pada papan sirkuit elektronik
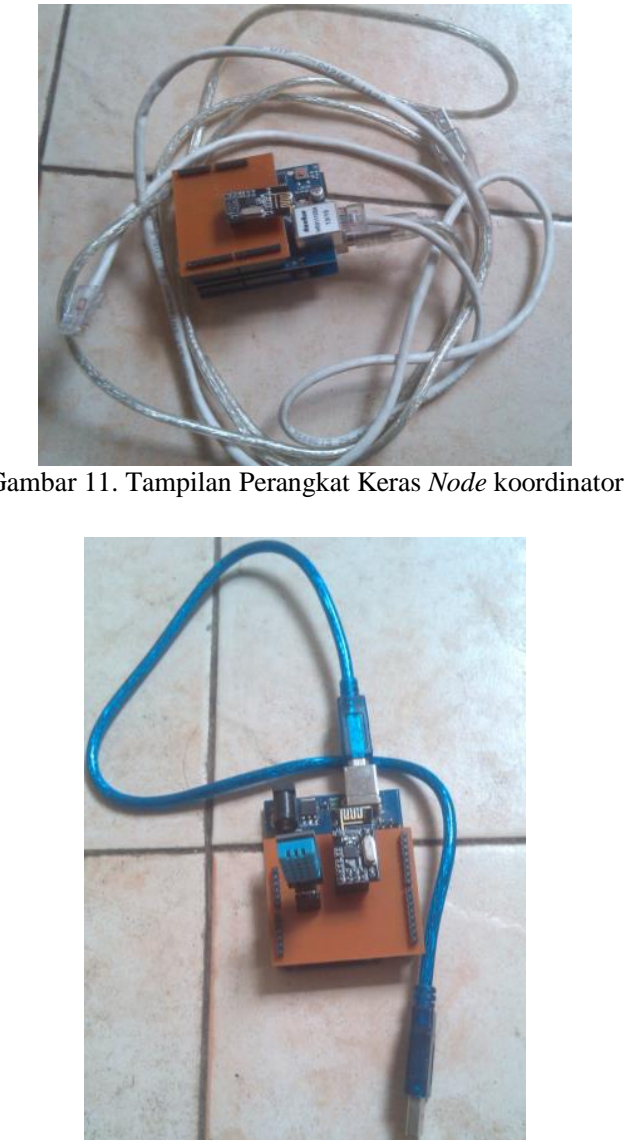

Gambar 12. Tampilan perangkat keras node sensor

Implementasi perangkat lunak dilakukan dengan memprogram masing-masing node, yaitu node koordinator dengan node sensor. Pemrograman dilakukan sesuai dengan fungsi dari node masing-masing. Program tersebut kemudain diunggah ke papan Arduino Uno.

\subsection{Pengujian Kerja Sistem}

Terdapat dua skenario yang akan dilakukan dalam pengujian yang masing-masing akan mencakup skenario pengujian fungsional dan pengujian kehandalan sistem. Pengujian fungsional akan menguji protokol komunikasi pada sub sistem node sensor dan sub sistem sub sistem node koordinator. Sedangkan kehandalan sistem akan menguji jarak maksimal agar node sensor dan node koordinator bisa saling berkomunikasi, dan menguji akuisisi data dari sensor DHT11 pada node sensor.

\subsubsection{Pengujian Fungsional}

a. Sub Sistem Node Sensor

Pengujian sub sistem node sensor terlihat pada Gambar 13 dan Gambar 14 bahwa node sensor 1 dan node sensor 2 dapat mengirim data hasil pengukuran sensor ke node koordinator setelah mendapat pesan "ping" dari node koordinator ini ditandai dengan pesan pada serial monitor "data telah dikirim" dan LED akan menyala. Sistem juga mampu menampilkan kegagalan komunikasi jika sub sistem node sensor tidak dapat mengirim data hasil pengukuran sensor ke node koordinator setelah mendapat pesan "ping" dari node koordinator ini ditandai dengan pesan pada serial monitor "data gagal dikirim" dan LED akan mati. 


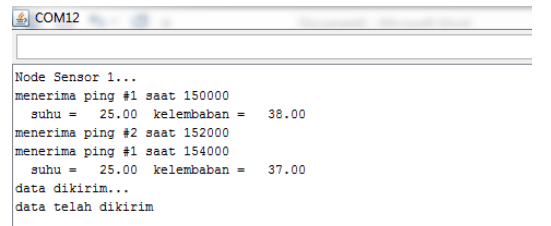

Gambar 13. Tampilan serial monitor di node sensor 1

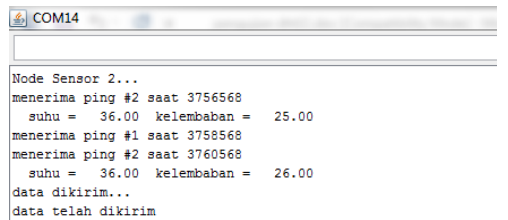

Gambar 14. Tampilan serial monitor di node sensor 2

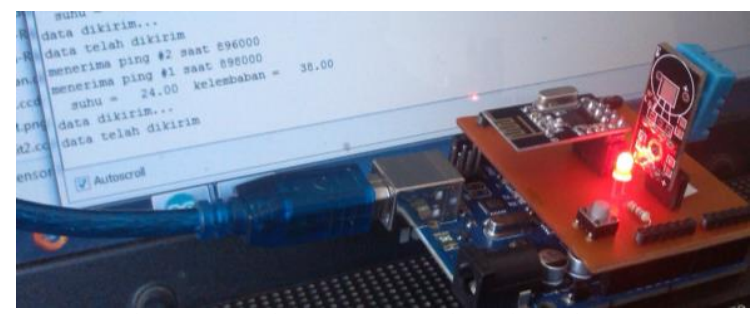

Gambar 15. Gambar LED menyala pada node sensor 1

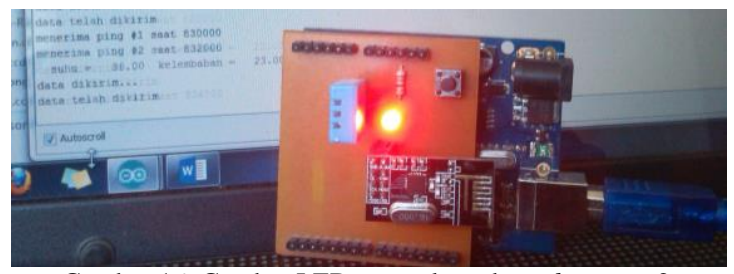

Gambar 16. Gambar LED menyala pada node sensor 2

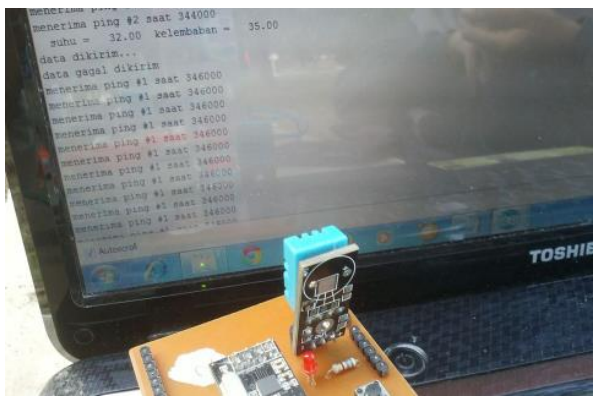

Gambar 17. Gambar LED mati saat data gagal dikirim

\section{b. Sub Sistem Node Koordinator}

Pengujian sub sistem node koordinator dikatakan berhasil seperti pada Gambar 18 dan Gambar 19 karena:

$>$ Sistem dapat meminta data dan menerima data dari node sensor.

$>$ Sistem dapat mengirim data melalui Ethernet Shield dengan menggunakan kabel UTP ke layanan web dan hasilnya sama dengan data yang ditampilkan pada serial monitor di sisi node sensor.

$>$ Sistem mampu mendeteksi status dari node sensor apakah "on" atau "off". Status "off” akan muncul jika node koordinator tidak berhasil mengirim permintaan berupa pesan "ping" pada node sensor selama $3 \mathrm{kali}$ berturut-turut.

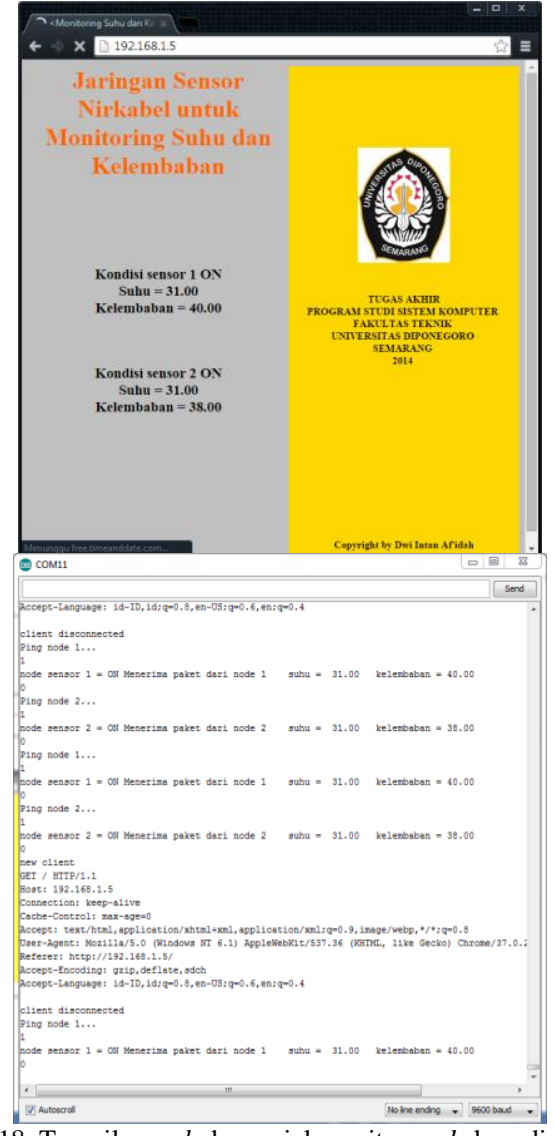

Gambar 18. Tampilan web dan serial monitor node koordinator ke-1

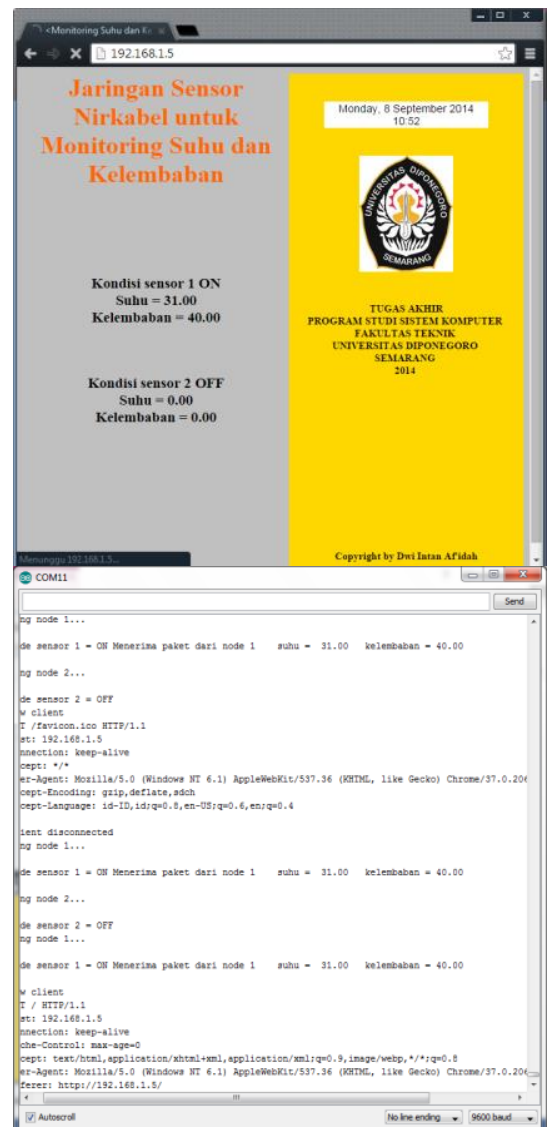

Gambar 19. Tampilan web dan serial monitor node koordinator ke-2 


\subsubsection{Pengujian Kehandalan Sistem Akuisis Data Sensor DHT11}

Pengujian sub sistem akuisisi data terdiri dari 2 sub sistem, yaitu akuisisi data suhu dan akuisisi data kelembaban. Pengambilan data dilakukan pada jam 16.40 WIB dengan pengaturan suhu $\mathrm{AC}$ sebesar $25^{\circ} \mathrm{C}$ serta kecepatan kipas tinggi. Semua kondisi diambil di Laboratorium Embedded dan Robotika Program Studi Sistem Komputer tanpa perlakuan khusus lainnya, kecuali ada faktor eksternal seperti cuaca dan lingkungan yang berubah sangat cepat. Data pembanding yang digunakan dalam pengujian sistem ini adalah pengukuran suhu dan kelembaban yang dibaca melalui HTC-1 Temperature and Humidity Meter.

a. Pengujian akuisisi data suhu node sensor 1

Pengambilan data serta pengukuran kesalahan pembacaan suhu pada pengujian akuisisi data suhu node sensor 1 terhadap data pembanding berupa hasil pembacaan suhu dari HTC-1 Temperature and Humidity Meter, dapat dilihat pada Gambar 20.

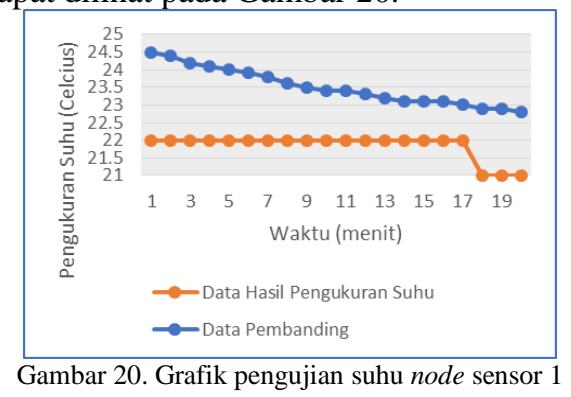

Berdasarkan Gambar 20, rata-rata kesalahan pembacaan suhu antara data DHT11 node sensor 1 pada suhu AC $25^{\circ} \mathrm{C}$ adalah $1,66^{\circ} \mathrm{C}$. Kesalahan $1,565^{\circ} \mathrm{C}$ menjelaskan bahwa adanya perbedaan data dengan pengukuran menggunakan alat ukur digital, disebabkan karena akurasi dari pembacaan data sensor DHT 11 menurut datasheet dijelaskan bahwa kesalahan pembacaan sensor DHT 11 kurang lebih $2^{\circ} \mathrm{C}$.

\section{b. Pengujian akuisisi data suhu node sensor 2}

Pengambilan data serta pengukuran kesalahan pembacaan suhu pada pengujian akuisisi data suhu node sensor 2 terhadap data pembanding berupa hasil pembacaan suhu dari HTC-1 Temperature and Humidity Meter, dapat dilihat pada Gambar 21.

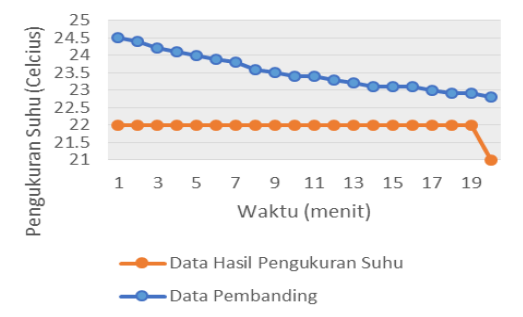

Gambar 21. Grafik pengujian suhu node sensor 2

Berdasarkan Gambar 21, rata-rata kesalahan pembacaan suhu antara data DHT11 di node sensor 2 dengan data pembanding pada suhu AC $25^{\circ} \mathrm{C}$ adalah $1,56^{\circ} \mathrm{C}$. Kesalahan $1,495^{\circ} \mathrm{C}$ menjelaskan bahwa adanya perbedaan data dengan pengukuran menggunakan alat ukur digital, disebabkan karena akurasi dari pembacaan data sensor DHT11 menurut datasheet dijelaskan bahwa kesalahan pembacaan sensor DHT11 kurang lebih $2^{\circ} \mathrm{C}$.

\section{c. Pengujian akuisisi data kelembaban node sensor 1}

Pengambilan data serta pengukuran kesalahan pembacaan kelembaban pada pengujian akuisisi data suhu node sensor 1 terhadap data pembanding berupa hasil pembacaan kelembaban dari HTC-1 Temperature and Humidity Meter, dapat dilihat pada Gambar 4.17.

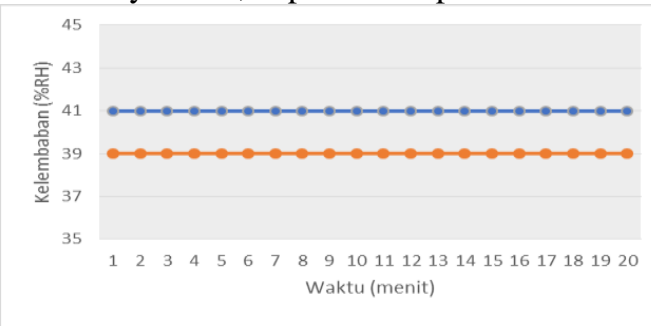

Gambar 22. Grafik pengujian kelembaban node sensor 2

Berdasarkan Gambar 22, rata-rata kesalahan pembacaan kelembaban antara data DHT11 di node sensor 1 dengan data pembanding pada suhu AC $25^{\circ} \mathrm{C}$ adalah $2 \%$. Kesalahan 2\% menjelaskan bahwa adanya perbedaan data dengan pengukuran menggunakan alat ukur digital, disebabkan karena akurasi dari pembacaan data sensor DHT 11 menurut datasheet dijelaskan bahwa kesalahan pembacaan kelembaban sensor DHT 11 kurang lebih 5\%.

\section{d. Pengujian akuisisi data kelembaban node sensor 2}

Pengambilan data serta pengukuran kesalahan pembacaan kelembaban pada pengujian akuisisi data suhu node sensor 1 terhadap data pembanding berupa hasil pembacaan kelembaban dari HTC-1 Temperature and Humidity Meter, dapat dilihat pada Gambar 23.

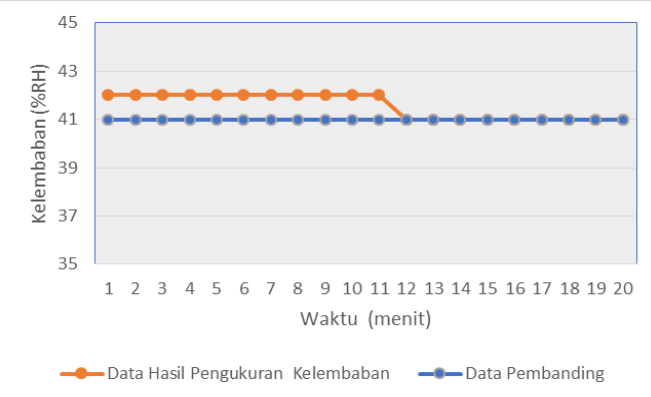

Gambar 23. Grafik pengujian kelembaban node sensor 2

Berdasarkan Gambar 23, rata-rata kesalahan pembacaan pengukuran kelembaban antara data DHT11 di node sensor 2 dengan data pembanding pada suhu AC $25^{\circ} \mathrm{C}$ adalah $1,1 \%$. Kesalahan $1,1 \%$ menjelaskan bahwa adanya perbedaan data dengan pengukuran menggunakan alat ukur digital, disebabkan karena akurasi dari pembacaan data sensor DHT 11 menurut datasheet dijelaskan bahwa kesalahan pembacaan kelembaban sensor DHT 11 kurang lebih 5\%.

Hasil pengujian node sensor 1 dan node sensor 2 dengan data pembanding dari HTC-1 Thermometer Humidity Meter dapat diketahui bahwa akuisisi suhu pada 
node sensor cukup handal, pada node sensor 1 pengukuran kesalahan $1,66^{\circ} \mathrm{C}$ dan pada node sensor 2 pengukuran kesalahan $1,56^{\circ} \mathrm{C}$ dari kesalahan pembacaan $2^{\circ} \mathrm{C}$ yang dijelaskan pada datasheet DHT11. Sedangkan untuk akuisisi kelembaban pada node sensor 1 dan node sensor 2 dapat dikatakan juga cukup handal, pada pada node sensor 1 pengukuran kesalahan $2 \%$ dan pada node sensor 2 pengukuran kesalahan $1,1 \% \mathrm{C}$ dari kesalahan pembacaan $5 \%$ yang dijelaskan pada datasheet DHT11.

Perbedaan akuisisi node sensor 1 dengan node sensor 2 terjadi karena masing-masing sensor memiliki sensitivitas berbeda meskipun menggunakan tipe sensor yang sama. Pembacaan sensor DHT11 yang menghasilkan data integer membuat akurasi kurang baik. pembacaan sensor ini kurang baik. Pada pengukuran suhu dan kelembaban node sensor 1 dan node sensor 2 terlihat adanya perbedaan, namun tidak terlalu signifikan sehingga hal ini masih dalam kewajaran.

\subsubsection{Kehandalan Berdasarkan Jangkauan Terjauh Sistem}

Mampu Berkomunikasi dengan Baik

Pengujian kehandalan berdasarkan jangkauan terjauh antara node sensor dan node koordinator yang mampu berkomunikasi dengan baik diperlukan untuk mengetahui jangkauan maksimal dari sistem ini. Sistem di uji dalam beberapa jangkauan dimulai dari jangkauan 85 meter sampai dengan 100 meter dengan pengukuran 10 kali tiap selisih 5 meter. Hasil pengiriman data dilihat melalui serial monitor. Setelah mendapatkan data yang menunjukkan komunikasi tidak berjalan dengan baik, maka jangkauan tersebut akan menjadi batas untuk tidak melakukan pengujian pada jangkaun yang lebih panjang lagi. Setelah itu, dilakukan pengujian untuk jangkauan yang lebih pendek dengan selisih per meter dari jangakauan batas. Pengujian dihentikan dan dilanjutkan pada jangkauan yang lebih pendek saat adanya indikasi komunikasi tidak berjalan dengan baik.

Pengujian dimulai dengan komunikasi antara node koordinator dan node sensor 1 terlebih dahulu kemudian dilanjutkan dengan pengujian komunikasi antara node koordinator dan node sensor 2.

a. Pengujian komunikasi antara node koordinator dan node sensor 1

Hasil pengujian pada jangkauan 90 meter, sistem masih berjalan dengan baik. Sedangkan pada jangkauan 95 meter, beberapa kali sistem mengalami kegagalan pengiriman data. Karena itu dilakukan pengujian jangakauan node sensor 1 dari 95 ke jangkauan yang lebih pendek dengan selisih tiap 1 meter dilakukan pengujian hingga mendapatkan data seperti pada Tabel 10.

Tabel 10. Pengujian node koordinator dan node sensor 1

\begin{tabular}{|c|c|c|c|c|c|c|c|}
\hline \multirow{2}{*}{$\begin{array}{c}\mathrm{N} \\
\mathrm{O}\end{array}$} & \multicolumn{2}{|c|}{$\begin{array}{c}\text { Node } \\
\text { Koordinato } \\
\text { r sebagai } \\
\text { Pengirim } \\
\end{array}$} & \multicolumn{3}{|c|}{ Informasi di Node Sensor 1} & \multicolumn{2}{|c|}{$\begin{array}{l}\text { Node Koordinator } \\
\text { sebagai Penerima }\end{array}$} \\
\hline & $\begin{array}{c}\text { Veri } \\
\text { fika } \\
\text { si } \\
\text { ping }\end{array}$ & $\begin{array}{l}\text { Sta } \\
\text { tus }\end{array}$ & $\begin{array}{l}\mathrm{Su} \\
\mathrm{hu}\end{array}$ & $\begin{array}{c}\text { Kelem- } \\
\text { baban }\end{array}$ & Status & Suhu & $\begin{array}{c}\text { Kelem- } \\
\text { baban }\end{array}$ \\
\hline \multicolumn{8}{|c|}{ Jangkauan 94 meter } \\
\hline 1 & $\mathrm{~T}$ & ON & 33 & 31 & $\begin{array}{c}\text { data telah } \\
\text { dikirim }\end{array}$ & 33 & 31 \\
\hline
\end{tabular}

\begin{tabular}{|c|c|c|c|c|c|c|c|}
\hline 2 & $\mathrm{~T}$ & $\mathrm{ON}$ & 33 & 31 & $\begin{array}{c}\text { data telah } \\
\text { dikirim }\end{array}$ & 33 & 31 \\
\hline 3 & $\mathrm{~T}$ & $\mathrm{ON}$ & 33 & 31 & $\begin{array}{c}\text { data telah } \\
\text { dikirim }\end{array}$ & 33 & 31 \\
\hline 4 & $\mathrm{~T}$ & $\mathrm{ON}$ & 33 & 31 & $\begin{array}{c}\text { data telah } \\
\text { dikirim }\end{array}$ & 33 & 31 \\
\hline 5 & $\mathrm{~T}$ & $\mathrm{ON}$ & 33 & 31 & $\begin{array}{c}\text { data gagal } \\
\text { dikirm }\end{array}$ & nan & nan \\
\hline \multicolumn{7}{|c|}{ Jangakaun 93 meter } \\
\hline 1 & $\mathrm{~T}$ & ON & 33 & 31 & $\begin{array}{c}\text { data telah } \\
\text { dikirim }\end{array}$ & 33 & 31 \\
\hline 2 & $\mathrm{~T}$ & ON & 33 & 31 & $\begin{array}{c}\text { data telah } \\
\text { dikirim }\end{array}$ & 33 & 31 \\
\hline 3 & $\mathrm{~T}$ & $\mathrm{ON}$ & 33 & 31 & $\begin{array}{c}\text { data telah } \\
\text { dikirim }\end{array}$ & 33 & 31 \\
\hline 4 & $\mathrm{~T}$ & $\mathrm{ON}$ & 33 & 31 & $\begin{array}{c}\text { data telah } \\
\text { dikirim }\end{array}$ & 33 & 31 \\
\hline 5 & $\mathrm{~T}$ & $\mathrm{ON}$ & 33 & 31 & $\begin{array}{c}\text { data telah } \\
\text { dikirim }\end{array}$ & 33 & 31 \\
\hline 6 & $\mathrm{~T}$ & ON & 33 & 31 & $\begin{array}{c}\text { data telah } \\
\text { dikirim }\end{array}$ & 33 & 31 \\
\hline 7 & $\mathrm{~T}$ & $\mathrm{ON}$ & 33 & 31 & $\begin{array}{c}\text { data telah } \\
\text { dikirim }\end{array}$ & 33 & 31 \\
\hline 8 & $\mathrm{~T}$ & ON & 33 & 31 & $\begin{array}{c}\text { data telah } \\
\text { dikirim }\end{array}$ & 33 & 31 \\
\hline 9 & $\mathrm{~T}$ & $\mathrm{ON}$ & 33 & 31 & $\begin{array}{c}\text { data telah } \\
\text { dikirim }\end{array}$ & 33 & 31 \\
\hline 10 & $\mathrm{~T}$ & $\mathrm{ON}$ & 33 & 31 & $\begin{array}{c}\text { data telah } \\
\text { dikirim }\end{array}$ & 33 & 31 \\
\hline
\end{tabular}

*Keterangan:

$\mathrm{T}$ : True, node koordinator berhasil mengirim permintaan ke node sensor $\mathrm{F}$ : False, node koordinator berhasil mengirim permintaan ke node sensor

Pada node sensor 1, dengan adanya indikasi node dapat menerima permintaan dari node koordinator berupa "ping" dan mampu mengirim data serta menampilkan pesan "data telah dikirim" dengan baik, maka diketahui bahwa jangkauan maksimal dari node sensor 1 ke node koordinator adalah 93 meter.

b. Pengujian komunikasi antara node koordinator dan node sensor 2

Hasil pengujian pada jangkauan 95 meter, sistem masih berjalan dengan baik. Sedangkan pada jangkauan 100 meter, beberapa kali sistem mengalami kegagalan pengiriman data. Karena itu dilakukan pengujian jangakauan dari 100 meter ke jangkauan yang lebih pendek dengan selisih tiap 1 meter dilakukan pengujian hingga mendapatkan data seperti pada Tabel 11.

Tabel 11. Pengujian node koordinator dan node sensor 2

\begin{tabular}{|c|c|c|c|c|c|c|c|}
\hline \multirow{2}{*}{$\begin{array}{l}\mathrm{N} \\
\mathrm{O}\end{array}$} & \multicolumn{2}{|c|}{$\begin{array}{c}\text { Node } \\
\text { Koordinato } \\
\text { r sebagai } \\
\text { Pengirim }\end{array}$} & \multicolumn{3}{|c|}{ Informasi di Node Sensor 2} & \multicolumn{2}{|c|}{$\begin{array}{c}\text { Node } \\
\text { Koordinator } \\
\text { sebagai } \\
\text { Penerima }\end{array}$} \\
\hline & $\begin{array}{l}\text { Veri } \\
\text { fika } \\
\text { si } \\
\text { ping }\end{array}$ & $\begin{array}{l}\text { Sta } \\
\text { tus }\end{array}$ & $\begin{array}{l}\text { Su } \\
\text { hu }\end{array}$ & $\begin{array}{c}\text { Kelem- } \\
\text { baban }\end{array}$ & Status & $\begin{array}{l}\mathrm{Su} \\
\mathrm{hu}\end{array}$ & $\begin{array}{c}\text { Kelem- } \\
\text { baban }\end{array}$ \\
\hline \multicolumn{8}{|c|}{ Jangakauan 99 meter } \\
\hline 1 & $\mathrm{~T}$ & ON & 34 & 32 & $\begin{array}{c}\text { data telah } \\
\text { dikirim }\end{array}$ & 34 & 32 \\
\hline 2 & $\mathrm{~F}$ & - & - & - & - & - & - \\
\hline \multicolumn{8}{|c|}{ Jangakauan 98 meter } \\
\hline 1 & $\mathrm{~T}$ & ON & 34 & 32 & $\begin{array}{c}\text { data telah } \\
\text { dikirim }\end{array}$ & 34 & 32 \\
\hline 2 & $\mathrm{~T}$ & $\mathrm{ON}$ & 34 & 32 & $\begin{array}{c}\text { data telah } \\
\text { dikirim }\end{array}$ & 34 & 32 \\
\hline 3 & $\mathrm{~T}$ & $\mathrm{ON}$ & 35 & 32 & $\begin{array}{c}\text { data telah } \\
\text { dikirim }\end{array}$ & 35 & 32 \\
\hline
\end{tabular}




\begin{tabular}{|c|c|c|c|c|c|c|c|c|}
\hline 4 & $\mathrm{~T}$ & $\mathrm{ON}$ & 35 & 32 & $\begin{array}{c}\text { data telah } \\
\text { dikirim }\end{array}$ & 35 & 32 \\
\hline 5 & $\mathrm{~T}$ & $\mathrm{ON}$ & 34 & 32 & $\begin{array}{c}\text { data telah } \\
\text { dikirim }\end{array}$ & 35 & 32 \\
\hline 6 & $\mathrm{~T}$ & $\mathrm{ON}$ & 35 & 32 & $\begin{array}{c}\text { data gagal } \\
\text { dikirim }\end{array}$ & nan & nan \\
\hline 1 & $\mathrm{~T}$ & $\mathrm{ON}$ & 35 & 32 & $\begin{array}{c}\text { data telah } \\
\text { dikirim }\end{array}$ & 35 & 32 \\
\hline 2 & $\mathrm{~T}$ & $\mathrm{ON}$ & 35 & 32 & $\begin{array}{c}\text { data telah } \\
\text { dikirim }\end{array}$ & 35 & 32 \\
\hline 3 & $\mathrm{~T}$ & $\mathrm{ON}$ & 35 & 32 & $\begin{array}{c}\text { data telah } \\
\text { dikirim }\end{array}$ & 35 & 32 \\
\hline 4 & $\mathrm{~T}$ & $\mathrm{ON}$ & 35 & 32 & $\begin{array}{c}\text { data telah } \\
\text { dikirim }\end{array}$ & 35 & 32 \\
\hline 5 & $\mathrm{~T}$ & $\mathrm{ON}$ & 35 & 32 & $\begin{array}{c}\text { data telah } \\
\text { dikirim }\end{array}$ & 35 & 32 \\
\hline 6 & $\mathrm{~T}$ & $\mathrm{ON}$ & 35 & 32 & $\begin{array}{c}\text { data telah } \\
\text { dikirim }\end{array}$ & 35 & 32 \\
\hline 7 & $\mathrm{~T}$ & $\mathrm{ON}$ & 35 & 32 & $\begin{array}{c}\text { data telah } \\
\text { dikirim }\end{array}$ & 35 & 32 \\
\hline 8 & $\mathrm{~T}$ & $\mathrm{ON}$ & 35 & 32 & $\begin{array}{c}\text { data telah } \\
\text { dikirim }\end{array}$ & 35 & 32 \\
\hline 10 & $\mathrm{~T}$ & $\mathrm{ON}$ & 35 & 32 & $\begin{array}{c}\text { data telah } \\
\text { dikirim }\end{array}$ & 35 & 32 \\
\hline
\end{tabular}

Perbedaan jangkauan komunikasi antara node yang satu dengan node yang lainnya dapat dijadikan pertimbangan dalam pengambilan keputusan jangkauan maksimal saat pengimplemtasian sistem. Mengingat jangakaun maksimal masing-masing node berbeda-bdea, maka pengambilan keputusan jangkauan maksimal saat pengimplemtasian sistem didasarkan pada jangakauan maskimal dimana kedua node mampu berkomunkasi dengan baik.

\subsection{Kesimpulan}

\section{PENUTUP}

Dari hasil pengujian yang dilakukan terhadap sistem jaringan sensor nirkabel untuk memantau suhu dan kelembaban, maka dapat disimpulkan sebagai berikut :

1. Node sensor dapat berjalan dengan baik berdasarkan fungsi dan kehandalan sistem. Hal ini ditunjukkan dengan:

a. Node sensor dapat menerima permintaan data berupa pesan "ping" dari node koordinator dan dapat mengirim data suhu dan kelembaban ke node koordinator.

* Keterangan :

$\mathrm{T}$ : True, node koordinator berhasil mengirim permintaan ke node sensor.

F : False, node koordinator berhasil mengirim permintaan ke node sensor

Pada node sensor 2, dengan adanya indikasi node dapat menerima permintaan dari node koordinator berupa "ping" dan mampu mengirim data serta menampilkan pesan "data telah dikirim" dengan baik, maka diketahui bahwa jangkauan maksimal dari node sensor 2 ke node koordinator adalah 97 meter. Node koordinator seperti Tabel 11 terlihat pada jangkaun 98 meter masih dapat mengirimkan pesan "ping" dan node senor juga masih dapat menerima pesan "ping". Akan tetapi, ada saat node sensor mengalami kegagalan saat mengirimkan data suhu dan kelembaban sehingga node koordinator memunculkan nilah "nan" pada suhu dan kelembaban. Hal ini megindikasikan bahwa jangkauan maksimal dari node koordinator ke node sensor addalah 98 meter.

Berikut tabel hasil pengujian berdasarkan jangkauan terjauh dimana sistem masih mampu berkomunikasi dengan baik.

Tabel 13. Hasil pengujian jangkauan maksimal

\begin{tabular}{|c|l|l|c|}
\hline No & \multicolumn{1}{|c|}{ Pengirm } & \multicolumn{1}{|c|}{ Penerima } & $\begin{array}{c}\text { Jangakauan } \\
\text { (meter) }\end{array}$ \\
\hline 1 & Node Koordinator & Node Sensor 1 & 98 \\
\hline & & Node Sensor 2 & 98 \\
\hline 2 & Node Sensor 1 & Node Koordinator & 93 \\
\hline 3 & Node Sensor 2 & Node Koordinator & 97 \\
\hline
\end{tabular}

Adanya perbedaan jangkauan komunikasi jangkauan antara node yang satu dengan yang lain terletak pada modul komunikasinya, dalam hal ini NRF24L01+. Faktorfaktor yang mempengaruhi komunikasi adalah frekuensi, TX gen, dan sensitivitas RX. Dalam sistem ini frekuensi tidak berpengaruh karena modul komunikasi yang digunakan itu sama yaitu NRF24L01+. Sehingga faktorfaktor yang dimungkinkan mempengaruhi jangkaun komunikasi TX gain dan sensitivitas RX pada modul komunikasi tersebut.

b. Node sensor mampu membaca data suhu dan kelembaban yang diambil dari sensor DHT11. Pengujian kesalahan pembacaan sensor suhu pada node sensor 1 adalah $1,565^{\circ} \mathrm{C}$ dan pada node sensor 2 adalah $1,495^{\circ} \mathrm{C}$ dibandingkan dengan pembacaan suhu pada HTC-1, sedangkan pengujian kesalahan pembacaan sensor kelembaban pada node sensor 1 adalah 2\% dan pada node sensor 2 adalah 1,1\% dibandingkan dengan pembacaan kelmebaban pada HTC-1.

2. Node koordinator dapat berjalan dengan baik berdasarkan fungsi dan kehandalan sistem. Hal ini ditunjukkan dengan:

a. Node koordinator dapat mengirim permintaan data berupa pesan "ping" ke node sensor dan dapat menerima data suhu dan kelembaban dari node sensor.

b. Node koordinator mampu membedakan data yang diterima dari node sensor 1 dan data yang diterima dari node sensor 2.

c. Data yang ditampilkan di halman web sudah sesuai dengan data yang ditampilkan di serial monitor pada sisi node koordinator.

3. Komunikasi dari sistem jaringan sensor nirkabel ini mampu berjalan dengan baik. Hal ini ditunjukkan dengan:

a. Sistem jaringan sensor nirkabel dapat memantau suhu dan kelembaban di beberapa titik.

b. Protokol komunikasi yang digunakan diawali dengan permintaan node koordinator ke node sensor terlebih dahulu sehingga terjadinya tumbukan data dapat diatasi.

c. Modul NRF24L01+ merupakan modul komunikasi data yang handal sehingga data yang diterima oleh suatu node sesuai dengan data yang dikirim oleh node yang lain. 
d. Jangkauan komunikasi sistem cukup handal hanya berbeda kurang lebih 7 meter dari jangakauan 100 meter yang dijelaskan oleh datasheet. Pengujian jangkauan yang dilakukan pada NRF24L01+ menghasilkan data jangakaun antara node koordinator sebagai pengirim dengan node sensor 1 dan node sensor 2 sebagai penerima adalah 98 meter, jangkauan antara node sensor 1 sebagai pengirim dengan node koordinator penerima adalah 93 meter, serta jangkauan jangkauan antara node sensor 2 sebagai pengirim dengan node koordinator penerima adalah 97 meter. Modul komunikasi data memiliki jangkauan yang berbeda-beda karena pengaruh frekuensi, TX gain, dan sensitivitas RX.

\subsection{Saran}

Berdasarkan hasil pengujian dan pengukuran yang dilakukan terhadap jaringan sensor nirkabel untuk memantau suhu dan kelembaban menggunakan NRF24L01+, dapat diberikan beberapa saran untuk pengembangan yang dapat dilakukan pada tugas akhir ini yaitu :

1. Sistem ini dapat dikembangkan untuk multimode sensor (lebih dari 2 node sensor) dengan cara menggunakan array pada pemrogramannya.

2. Penggunaan sensor suhu dan kelembaban, disarankan tidak menggunakan sensor DHT11 karena akurasi sensornya kurang baik, yaitu hanya bisa menampilkan nilai integer.

3. Sistem ini dapat dikembangkan menggunakan sensor selain suhu dan kelembaban. Misal, sensor gas TGS4160 untuk mendeteksi kadar CO2 untuk memantau kualiatas udara di suatu area.

4. Halaman web pada sistem ini dapat dikembangkan lebih lanjut sehingga data dapat diolah dan dianalis serta diinterpretasikan dalam bentuk grafik.

\section{DAFTAR PUSTAKA}

[1] Chung, W., J.F. Villaverde, and J. Tan, "Wireless Sensor Network Based Soil Moisture Monitoring System Design", Paper of The 2013 Federated Conferencee on Computer Science and Information System, 79-82, 2013.

[2] Kuorilehto, M., System Level Design Issue in Low-Power Wireless Sensor Networks, Tampere, Findland, 2008

[3] Munir, M.S., Rancangan Smart Greenhouse dengan Teknologi Mobile untuk Efisiensi Tenaga, Biaya dan waktu dalam Pengelolaan Tanaman, Skripsi S-1, Universitas Pembangunan Nasional Veteran, Jawa Timur, 2010.

[4] Rizalani, R., Desain dan Implementasi Jejaring Sensor Nirkabel Infra Merah untuk Sistem Informasi Parkir Gedung
Bertingkat, Tugas Akhir D-3, Politeknik Elektronika Negeri Surabaya, Surabaya, 2011

[5] Sonavane, S.S., B.P. Patil, and V. Kumar, "Experimentation for Packet Loss on MSP430 and nRF14L01+ Based Wireless Sensor Network", Journal of Advanced Networking and Applications, Vol.1, No.1, page 35-29, 2009.

[6] Susana, R., "Desain dan Implementasi Jejaring Sensor Nirkabel Infra Merah untuk Sistem Informasi Parkir Gedung Bertingkat", Jurnal Informatika, no. 2, vol 4, 2013.

[7] Townsend, C., S. Arms, "Design Principles of Wireless Sensor Networks Protocols for Control Applications", MicroStrain Inc, New York, 2010.

[8] --, $\quad$ Arduino $\quad$ Ethernet Shield, http://arduino.cc/en/Main/ArduinoEthernetShield, Mei 2014.

[9] --, Arduino Uno, http://arduino.cc/en/Main/arduinoBoardUno, Mei 2014.

[10] --,Datasheet Arduino Ethernet, http://arduino.cc/en/uploads/Main/PoE-datasheet.pdf , Mei 2014

[11] --,Datasheet DHT11, http://www.micro4you.com/files/sensor/DHT11.pdf, Mei 2014.

[12] --,Datasheet nRF24L01+, http://arduinoinfo.wikispaces.com/Nrf24L01-2.4GHz-HowTo, Mei 2014. 